\title{
Putative role of ischemic postconditioning in a rat model of limb ischemia and reperfusion: involvement of hypoxia-inducible factor- $1 \alpha$ expression
}

\author{
T. Wang ${ }^{1}$, Y.T. Zhou ${ }^{2}$, X.N. Chen ${ }^{3}$ and A.X. Zhu ${ }^{4}$ \\ ${ }^{1}$ Department of Anesthesiology, Shuyang People's Hospital, JiangSu, China \\ ${ }^{2}$ Department of General Surgery, Shuyang People's Hospital, JiangSu, China \\ ${ }^{3}$ Institute of Pathophysiology, School of Basic Medical Sciences, LanZhou University, Lanzhou, Gansu, China \\ ${ }^{4}$ Department of Pharmacy, Shuyang People's Hospital, JiangSu, China
}

\begin{abstract}
Hypoxia-inducible factor- $1 \alpha(\mathrm{HIF}-1 \alpha)$ is one of the most potent angiogenic growth factors. It improves angiogenesis and tissue perfusion in ischemic skeletal muscle. In the present study, we tested the hypothesis that ischemic postconditioning is effective for salvaging ischemic skeletal muscle resulting from limb ischemia-reperfusion injury, and that the mechanism involves expression of HIF- $1 \alpha$. Wistar rats were randomly divided into three groups ( $n=36$ each): sham-operated (group $S)$, hindlimb ischemia-reperfusion (group IR), and ischemic postconditioning (group IPO). Each group was divided into subgroups ( $n=6$ ) according to reperfusion time: immediate $\left(0 \mathrm{~h}, \mathrm{~T}_{0}\right), 1 \mathrm{~h}\left(\mathrm{~T}_{1}\right), 3 \mathrm{~h}\left(\mathrm{~T}_{3}\right), 6 \mathrm{~h}\left(\mathrm{~T}_{6}\right), 12 \mathrm{~h}\left(\mathrm{~T}_{12}\right)$, and $24 \mathrm{~h}\left(\mathrm{~T}_{24}\right)$. In the IPO group, three cycles of 30-s reperfusion and 30-s femoral aortic reocclusion were carried out before reperfusion. At all reperfusion times $\left(T_{0}-T_{24}\right)$, serum creatine kinase $(C K)$ and lactate dehydrogenase $(L D H)$ activities, as well as interleukin (IL)-6, IL-10, and tumor necrosis factor- $\alpha(\mathrm{TNF}-\alpha)$ concentrations, were measured in rats after they were killed. Histological and immunohistochemical methods were used to assess the skeletal muscle damage and HIF-1 $\alpha$ expression in skeletal muscle ischemia. In groups IR and IPO, serum LDH and CK activities and TNF- $\alpha$, IL-6, and IL-10 concentrations were all significantly increased compared to group $\mathrm{S}$, and HIF-1 $\alpha$ expression was up-regulated $(\mathrm{P}<0.05$ or $\mathrm{P}<0.01)$. In group IPO, serum LDH and CK activities and TNF- $\alpha$ and IL- 6 concentrations were significantly decreased, IL-10 concentration was increased, HIF- $1 \alpha$ expression was down-regulated $(\mathrm{P}<0.05$ or $\mathrm{P}<0.01)$, and the pathological changes were reduced compared to group IR. The present study suggests that ischemic postconditioning can reduce skeletal muscle damage caused by limb ischemiareperfusion and that its mechanisms may be related to the involvement of HIF-1 $\alpha$ in the limb ischemia-reperfusion injurytriggered inflammatory response.
\end{abstract}

Key words: Hypoxia-inducible factor- $1 \alpha$; Ischemic postconditioning; Skeletal muscle ischemia

\section{Introduction}

Ischemia-reperfusion (IR) injury occurs when tissue is reperfused following a period of ischemia, and results from acute inflammation involving various mechanisms. The effects of lower extremity IR occur across a spectrum ranging from mild injury with no lasting sequelae to a systemic response with multi-organ injury. This process may give rise to generalized inflammation with activation of different immune cells, release of a vast number of inflammatory mediators, reactive free radicals, and vasoactive substances $(1,2)$. Pro-inflammatory cytokines play a critical role in the cascade of events resulting in injury from
IR. In the literature, the role of interleukin (IL)-1 $\beta$, IL-6, IL-8, thromboxane $A_{2}\left(T_{X} A_{2}\right)$, and tumor necrosis factor-alpha $(T N F-\alpha)$ are well documented in IR injury. These cytokines provide signals between the responding leucocyte and the vascular endothelial barrier, and the net result is upregulation due to IR injury and loss of endothelial integrity as well as recruitment and activation of leukocytes (3-6).

Critical lower limb ischemia is a common cause for amputation. Clinical trials targeting neutrophil blockade and reactive oxygen species (ROS) scavenging (through free radical scavengers) have thus far failed to be successful 
$(7,8)$. To develop new therapeutic strategies, more information is needed about molecular mechanisms of tissue responses to ischemic stress and factors inducing angiogenesis. DNA array technology has offered a new powerful tool for research into the molecular pathophysiology of human disease. Tuomisto et al. (9) reported that gene transfer of vascular endothelial growth factor (VEGF), insulin-like growth factor-1 (IGF-1), and IGF-2 to induce angiogenesis, survival, and regeneration may be useful for treatment of chronically ischemic skeletal muscle. Hypoxiainducible factor- $1 \alpha(\mathrm{HIF}-1 \alpha)$, the major regulator of VEGF expression under hypoxia (10), was up-regulated at both the mRNA and the protein levels, and was located in the nucleus, suggesting that this may be the main pathway for VEGF induction in acute ischemia. Additionally, a recent study suggested that mutant HIF- $1 \alpha$ can improve mature angiogenesis and tissue perfusion in ischemic rabbit skeletal muscle (11). The processes of inflammation and angiogenesis are intimately linked. Research has suggested that inflammation and angiogenesis are interdependent processes aiding the growth and spread of cancer (12). However, to our knowledge, no investigations have yet been made into the problem of inflammation and its effect on angiogenesis in skeletal muscle ischemia from lower limb IR injury. Accordingly, the present study was performed to determine the role of ischemic postconditioning in skeletal muscle ischemia induced by limb ischemiareperfusion, and whether its mechanism involves HIF-1 $\alpha$ expression.

\section{Material and Methods}

\section{Animals and reagents}

Male Wistar rats, weighing $220-250 \mathrm{~g}$, were used in the experiments (Medical Experimental Animal Center of the Gansu College of Traditional Chinese Medicine, Lanzhou, China). All procedures were performed in accordance with the Declaration of Helsinki of the World Medical Association. The rats were maintained on standard rat chow, with water ad libitum, under specific pathogen-free conditions at constant temperature $\left(22-24^{\circ} \mathrm{C}\right)$.

Serum creatine kinase $(\mathrm{CK})$ and lactate dehydrogenase (LDH) assay kits were obtained from NanJing JianCheng Biotechnology Company (China). TNF- $\alpha$, IL-6, IL-10, anti-TNF- $\alpha$, anti-IL-6, and anti-IL-10 antibodies, and rat HIF- $1 \alpha$ assay kits were purchased from Wuhan Boster Bioengineering Institute (China). All other chemicals were of the highest purity commercially available.

\section{Models and grouping}

Animals were divided into three groups in a randomized manner, and each group contained 36 rats as follows: group 1 [sham-operated (S)], without ischemia; group 2 [limb ischemia-reperfusion (IR)], in which skeletal muscle IR injury was produced with the bilateral lower limb ligated for $3 \mathrm{~h}$ by placing an elastic rubber band

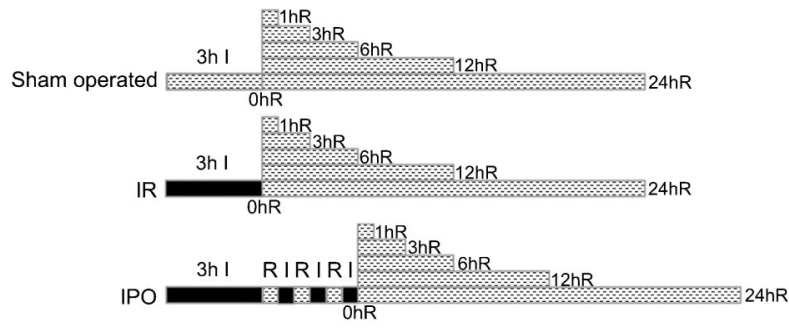

Figure 1. Experimental protocol used to determine the effect of one possible variation in ischemic postconditioning (IPO) on skeletal muscle after ischemia (I) and reperfusion $(R)$. In the sham-operated group $(n=36)$, there was no intervention; ischemia-reperfusion (IR, $\mathrm{n}=36$ ) consisted of $3 \mathrm{~h}$ of I followed by $0,1,3$, 6,12 , or $24 \mathrm{~h}$ of R; IPO $(n=36)$ consisted of $3 \mathrm{~h}$ of I followed by 3 cycles of $30 \mathrm{~s}$ of $\mathrm{R}$ and $30 \mathrm{~s}$ of $\mathrm{I}$, and then followed by $0,1,3,6,12$, or $24 \mathrm{~h}$ of $\mathrm{R}$, respectively.

under a pressure of $290-310 \mathrm{mmHg}$ on the proximal part of the lower limb $(13,14)$ and then releasing it to allow reperfusion; and group 3 [ischemic postconditioning (IPO)], in which, at the start of reperfusion, three cycles of 30-s reperfusion and 30-s femoral aortic reocclusion (15) preceded reperfusion, as shown in Figure $1(n=36)$. Each group was housed in wire mesh cages at room temperature with a 12:12-h day-night cycle. Prior to the experiment, all rats were fasted for $24 \mathrm{~h}$ and allowed access to tap water ad libitum. The animals were anesthetized with inhalation of $2 \sim 3 \%$ isoflurane (16), and the anesthesia was only maintained during the course of the experimental operation. The S, IR, and IPO groups were followed for $0,1,3,6,12$, or $24 \mathrm{~h}$ of reperfusion. Following reperfusion, blood samples from the inferior vena cava were obtained, and 6 rats were humanely killed by venous bloodletting and the skeletal muscle was removed immediately to collect tissue samples at each time point.

\section{Measurement of serum laboratory parameters}

Blood samples were centrifuged at $3000 \mathrm{~g}$ for $10 \mathrm{~min}$ at room temperature; the plasma was separated and transferred into clean 1.5-mL Eppendorf tubes before being stored at $-80^{\circ} \mathrm{C}$ until assay as a batch at a later date. Serum CK and LDH measurements were performed by standard spectrophotometry using an automated clinical chemistry analyzer (Olympus AU-2700, Japan). All assays were carried out in duplicate.

\section{Measurement of TNF- $\alpha$, IL-6, and IL-10 levels}

Serum TNF- $\alpha, \mathrm{IL}-6$, and IL-10 levels were measured by enzyme-linked immunosorbent assay (ELISA) according to the manufacturer's (Wuhan Boster Bioengineering Institute) instructions. From each time point (absorbance value), a viability value was calculated as a percentage of the average absorbance. All measurements were carried out in duplicate. 
Anti-TNF- $\alpha$, anti-IL-6, and anti-IL-10 antibodies

In a separate series of experiments, anti-TNF- $\alpha(1 \mathrm{~mL}$ of hyperimmune serum/animal), anti-IL-6 (1 mL/animal), or anti-IL-10 (1 mL/animal) was given iv $60 \mathrm{~min}$ before reperfusion.

\section{Histological assessment and scoring of tissue damage}

The murine skeletal muscle was incised along the quadriceps femoris muscle and fixed in 10\% phosphatebuffered formalin. The tissue was then embedded in paraffin and transverse sectioned at a thickness of $4 \mu \mathrm{m}$. Hematoxylin and eosin-stained slides were prepared from the tissue blocks using standard techniques. Quantitative analysis was performed for the level of tissue damage by an independent observer who was blinded to the identity of the study group from which each slide was produced. Sections were scored for the degree of damage, using a published scale of 1-10 (17), by an independent observer blinded to the nature of the specimens.

\section{Immunohistochemical staining of HIF-1a}

The best tissue section for immunohistochemistry was selected and the corresponding formalin-fixed, paraffinembedded resection specimen was obtained. Immunohistochemical detection of HIF- $1 \alpha$ was performed using the Image-Pro Plus 6.0 analysis system (Media Cybernetics Co., USA), which is based on streptavidin-biotin complex formation. Sections 4-mm thick were de-paraffinized and the antigen was retrieved by microwave treatment in $10 \mathrm{mmol} / \mathrm{L}$ citrate buffer, $\mathrm{pH} 6.0$, for $20 \mathrm{~min}$, followed by blocking steps carried out according to the manufacturer's protocol. Mouse monoclonal antibody (Wuhan Boster Co.), diluted 1:50-200, was applied and the slides were incubated overnight at $41^{\circ} \mathrm{C}$. The secondary antibody, biotinylated goat anti-mouse antibody (Wuhan Boster Co.), was applied with additional blocking precautions to minimize the amplification of nonspecific background. The antibody was visualized using diaminobenzidine, and the sections were counterstained with hematoxylin, dehydrated, and mounted. Substitution of the primary antibody with an autologous preimmune serum, and immunoadsorption with immunizing peptide served as a negative control. Batch-to-batch variation was assessed by choosing two sections showing high and low HIF-1 $\alpha$ expression and running additional sections from these biopsies with each batch.

Assessment of HIF-1 $\alpha$ staining in the tissue sections

The extent of hypoxia skeletal muscle tissue staining was quantified on 24-h specimens when the staining was greatest. Digital images of the skeletal muscle tissue overlying three regions of the quadriceps femoris were obtained using a microscope at $20 \times$ magnification. The total thickness of the skeletal muscle tissue and positive staining cells were measured using the Image-Pro software (Media Cybernetics Co.) In each region, five measurements were obtained and averaged. The HIF-1 $\alpha$ protein level is reported as the sum of the integrated optical density (SUM IOD) value in different groups. HIF-1 $\alpha$ was also assessed by an experienced pathologist who was unaware of the treatment

\section{Western blot analysis}

The excised quadriceps femoris muscles were homogenized in ice-cold buffer (8 M urea, $1 / 10 \mathrm{v} / \mathrm{v}$ glycerol, 1/20 v/v 20\% SDS, 1/200 v/v 1 M dithiothreitol, 1/100 v/v $0.5 \mathrm{M}$ Tris, adjusted to $\mathrm{pH} 6.8$ ) containing a protease inhibitor cocktail (Complete Mini, Roche, China), prior to PAGE and transfer onto polyvinylidene fluoride membranes (Wuhan Boster Co.). The membranes were incubated with either mouse monoclonal anti-HIF-1 $\alpha$ antibody (1:500, Wuhan Boster Co.) or rabbit polyclonal anti- $\beta$-actin antibody (1:2,000, Wuhan Boster Co.). Bound antibody was visualized with species-specific horseradish peroxidase-conjugated secondary antibody and a chemiluminescence system (Wuhan Boster Co.). Signals were quantified using a Gel Doc 2000 scanner with the Quantity One software (Media Cybernetics Co.). The densities of bands were normalized to $\beta$-actin.

\section{Statistical analysis}

Data were analyzed using the SPSS software (SPSS, USA) and are reported as means $\pm S D$. Data were analyzed by repeated measures analysis, and the means of all groups were compared using the least significant difference (LSD) test for multiple comparisons. $\mathrm{P}<0.05$ was considered to be significant.

\section{Results}

\section{Histology}

Skeletal muscle IR resulted in significant injury, as demonstrated by edema of skeletal muscle cells, sarcoplasm dissolution and necrosis, interstitial vessel hyperemia and hemorrhage, and neutrophil infiltration (Figure 2A-C). In contrast, IPO treatment ameliorated severe skeletal muscle damage (Figure 2A-C). According to the histopathology scores, $3 \mathrm{~h}$ of skeletal muscle ischemia followed by $3 \mathrm{~h}$ of reperfusion resulted in severe acute skeletal muscle lesions. Quantitative analysis showed significantly increased scores in the IR group compared with the $S$ group and decreased scores in the IPO group compared with the IR group $(P<0.01$, Figure 2D).

\section{Biochemical assessment of lower limb IR injury}

Measurement of serum CK and LDH activity revealed a significant increase in these parameters for both the IR and IPO groups, compared to the sham-operated animals $(\mathrm{P}<0.05$ or $\mathrm{P}<0.01$, Figure $3 \mathrm{~A}$ and $\mathrm{B})$. Compared with the IR group, the activity of CK in IPO rats was significantly decreased at $3,6,12$, and $24 \mathrm{~h}$ after reperfusion and the activity of LDH in IPO rats was significantly decreased at 1, 3 , 6,12 , and $24 \mathrm{~h}$ after reperfusion $(\mathrm{P}<0.01$; Figure $3 \mathrm{~A}$ and $\mathrm{B})$. 

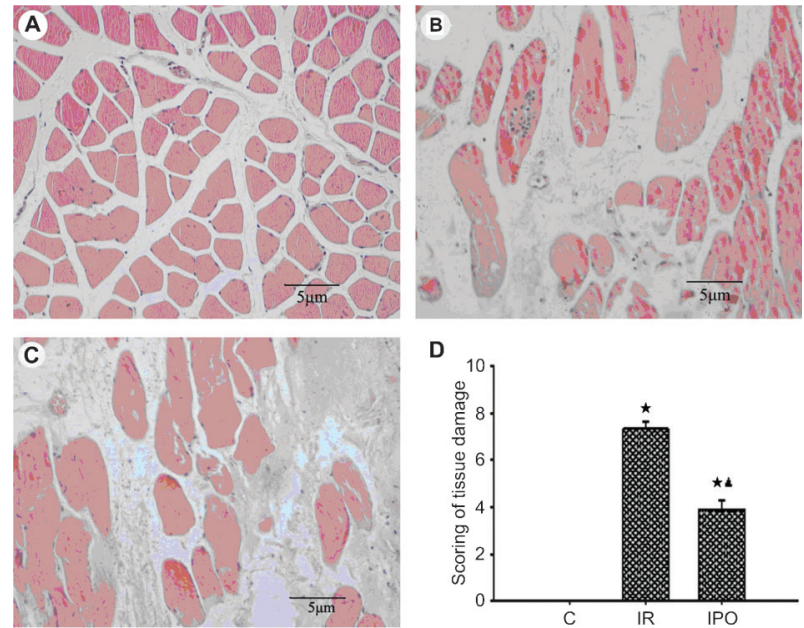

Figure 2. Histological evaluations of skeletal muscle tissue. Representative skeletal muscle sections were obtained $3 \mathrm{~h}$ after sham surgery or ischemia-reperfusion (IR). A, Section from sham-operated group. $B$, Section from IR group. $C$, Section from ischemic postconditioning (IPO) group. All of the sections were stained with hematoxylin and eosin. Scale bar $=5 \mu \mathrm{m}$. Skeletal muscle IR resulted in significant injury as demonstrated by skeletal muscle cells edema, sarcoplasm dissolution and necrosis, interstitial vessel hyperemia and hemorrhage, and neutrophil infiltration. However, IPO treatment ameliorated severe skeletal muscle damage. Note that there were significant differences in the changes of histological properties between sham-operated, IR, and IPO groups. $D$, Roach DM score for acute skeletal muscle lesions from sham-operated control (C), $I R$, and IPO groups $(n=36)$. Data are reported as means $\pm S D$. ${ }^{\star} \mathrm{P}<0.01$ vs sham-operated group; ${ }^{\mathbf{\Lambda}} \mathrm{P}<0.01$ vs IR group (oneway ANOVA).

\section{Changes in TNF- $\alpha$, IL-6, and IL-10 after IR of hindlimbs}

Compared with the $S$ group, the $I R$ rats showed a significant increase in serum TNF- $\alpha$, IL-6, and IL-10, and the increase peaked at 1,3 , and $3 \mathrm{~h}$ reperfusion, respectively $(P<0.01$; Figure $4 A-C)$. Compared with the IR group, serum TNF- $\alpha$ and IL- 6 gradually decreased after
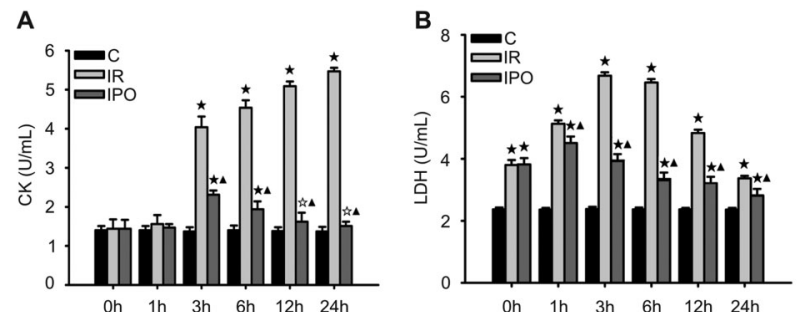

Figure 3. Leakage of necroenzyme creatine kinase (CK) and lactate dehydrogenase (LDH) after skeletal muscle ischemiareperfusion (IR) injury of $3 \mathrm{~h}$ of ischemia and $24 \mathrm{~h}$ of reperfusion $(\mathrm{n}=36)$. $A$, Serum CK activity. $B$, Serum LDH activity. Data are reported as means $\pm \mathrm{SD}$. ${ }^{\wedge} \mathrm{P}<0.05,{ }^{\star} \mathrm{P}<0.01$ vs sham-operated control group (C); ${ }^{\mathbf{A}} \mathrm{P}<0.01$ vs IR group (one-way ANOVA).
$1 \mathrm{~h}$ reperfusion $(\mathrm{P}<0.05$ or $\mathrm{P}<0.01$; Figure $4 \mathrm{~A}$ and $\mathrm{B}$ ), whereas the IL-10 increased significantly at $3 \mathrm{~h}$ reperfusion in the IPO group $(\mathrm{P}<0.01$; Figure $4 \mathrm{C})$.

\section{Expression of HIF-1 $\alpha$ in skeletal muscle injury after IR of hindlimbs}

Photomicrographs of HIF- $1 \alpha$ staining in the skeletal muscle tissues of all groups are shown in Figure 5A-C. The thickness of skeletal muscle specimens containing HIF-1 $\alpha$-positive skeletal muscle cells was determined at $3 \mathrm{~h}$ when the staining was greatest. HIF- $1 \alpha$ was seen in myocyte cytoplasm, vascular endothelial cytoplasm, and nuclei of skeletal muscle sham-operated rats, but expression increased in density, intensity, and extent with progression to skeletal muscle IR injury $(\mathrm{P}<0.01$; Figure $5 D)$. Compared with group IR, IPO treatments significantly decreased levels of HIF- $1 \alpha$ expression in myocyte cytoplasm and nuclei, vascular endothelial cytoplasm and nuclei, and inflammatory cytoplasm and nuclei of skeletal muscle tissue $(P<0.01$; Figure $5 D)$.

Quantitative Western blot analysis showed that limb IR and IPO increased the level of endogenous HIF- $1 \alpha$ protein and led to a 1.62- and 1.18-fold increase compared to group $\mathrm{S}$ muscle, respectively (both $\mathrm{P}<0.05$ ). Moreover, IPO treatment decreased in ischemic muscles about 0.73fold compared to group IR muscle $(P<0.05$; Figure $6 A)$.

\section{Effect of anti-TNF- $\alpha$, anti-IL-6, and anti-IL-10 on HIF-1 $\alpha$ expression in skeletal muscle}

We evaluated whether the effect of anti-TNF- $\alpha$, antiIL-6, or anti-IL-10 was correlated with inhibition or promotion of HIF- $1 \alpha$ expression in skeletal muscle injury induced by limb IR. Treatment with anti-TNF- $\alpha$ or anti-IL-6 tended to attenuate skeletal muscle injury and decreased expression of HIF- $1 \alpha$, whereas treatment with anti-IL-10 tended to enhance skeletal muscle injury and increased expression of HIF-1 $\alpha$ (Figure 6A-D).

\section{HIF- $1 \alpha$ and its relationship to inflammatory mediators}

The relationships amongst the changes in TNF- $\alpha$, IL6 , and IL-10 levels and the expression of HIF- $1 \alpha$ are shown for all conditions in Figures 4, 5, and 6. In the IR rats, the levels of TNF- $\alpha$, IL-6, and IL-10 increased and, consequently, the expression of HIF-1 $\alpha$ increased significantly also. In contrast, in the IPO group, in which the levels of TNF- $\alpha$ and IL- 6 decreased whereas that of IL-10 increased, the expression of HIF-1 $\alpha$ decreased.

\section{Discussion}

IR injury is a common and important clinical problem that affects many different organ systems including the brain (stroke and head injury), heart (myocardial infarction), and skeletal muscle. Although IR injury can affect every organ in the body, its effects on skeletal muscle are frequently quite devastating. The sequelae of the cellular 

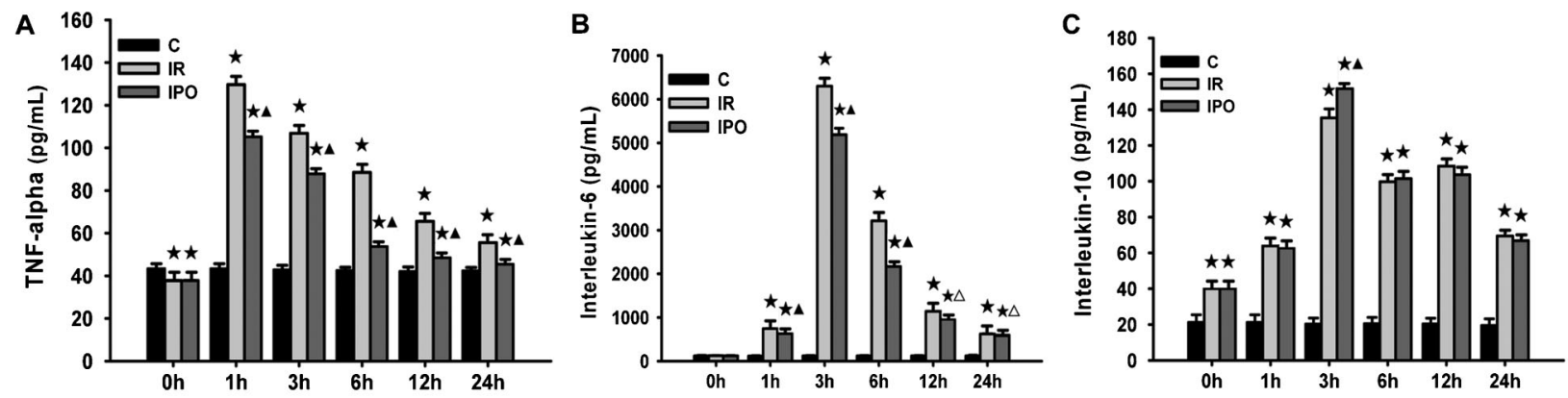

Figure 4. Inflammatory cytokine release after skeletal muscle ischemia-reperfusion (IR) injury of $3 \mathrm{~h}$ of ischemia and $24 \mathrm{~h}$ of reperfusion $(\mathrm{n}=36)$. A, Serum concentration of TNF- $\alpha$. B, Serum concentration of IL-6. C, Serum concentration of IL-10. Data are reported as means $\pm \mathrm{SD}$. ${ }^{\star} \mathrm{P}<0.01$ vs sham-operated control group $(\mathrm{C}) ;{ }^{\triangle} \mathrm{P}<0.05,{ }^{\wedge} \mathrm{P}<0.01$ vs IR group (one-way ANOVA).

injury of IR may lead to the loss of organ or limb function, or even death.

Critical limb ischemia is treated by percutaneous transluminal angioplasty or vascular surgery. However,
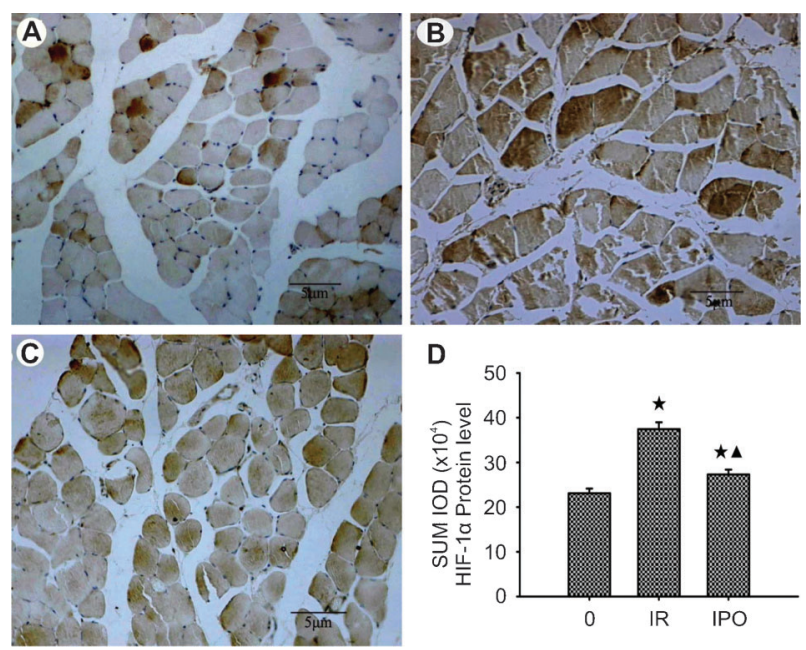

Figure 5. Photomicrographs of hypoxia-inducible factor- $1 \alpha$ (HIF$1 \alpha)$ immunohistochemistry in skeletal muscle tissue. The thickness of skeletal muscle containing HIF-1 $\alpha$-positive skeletal muscle cells was determined at $3 \mathrm{~h}$. Scale bar: $5 \mu \mathrm{m}$. A, Weak staining of skeletal muscle cytoplasm and nucleus, of vascular endothelial cytoplasm and nucleus, and of inflammatory cytoplasm and nucleus, in sham-operated control (C) group skeletal muscle. $B$, Strong staining of skeletal muscle cytoplasm and nucleus, of vascular endothelial cytoplasm and nucleus, and of inflammatory cytoplasm and nucleus, in ischemia-reperfusion (IR) group skeletal muscle. C, Moderate staining of skeletal muscle cytoplasm and nucleus, of vascular endothelial cytoplasm, and of inflammatory cytoplasm and nucleus, in ischemic postconditioning (IPO) group skeletal muscle. Note that there were significant differences in the expression of HIF- $1 \alpha$ between sham-operated, IR, and IPO groups. $D$, SUM IOD (integrated absorbance value) of HIF-1 $\alpha$ protein level in sham-operated, IR, and IPO groups of skeletal muscle tissue $(n=36)$. Data are reported as means $\pm S D$. ${ }^{\star} P<0.01$ vs sham-operated group; $\Delta \mathrm{P}<0.01$ vs IR group (one-way ANOVA).
$20-30 \%$ of patients with critical limb ischemia are not suitable candidates for these methods and may require amputation (18). Recently, a new technique, called "postconditioning" (15), describes a modified schedule of reperfusion characterized by intermittent restoration of blood flow after a prolonged episode of ischemia. Gyurkovics et al. (19) clearly demonstrated that the use of postconditioning may gain clinical relevance in infrarenal aortic surgery by being a potent shield to prevent postischemia-reperfusion syndrome.

Physiological and anatomical studies have shown that irreversible muscle cell damage starts after $3 \mathrm{~h}$ of ischemia and is nearly complete at $6 \mathrm{~h}(20-22)$. Therefore, we took
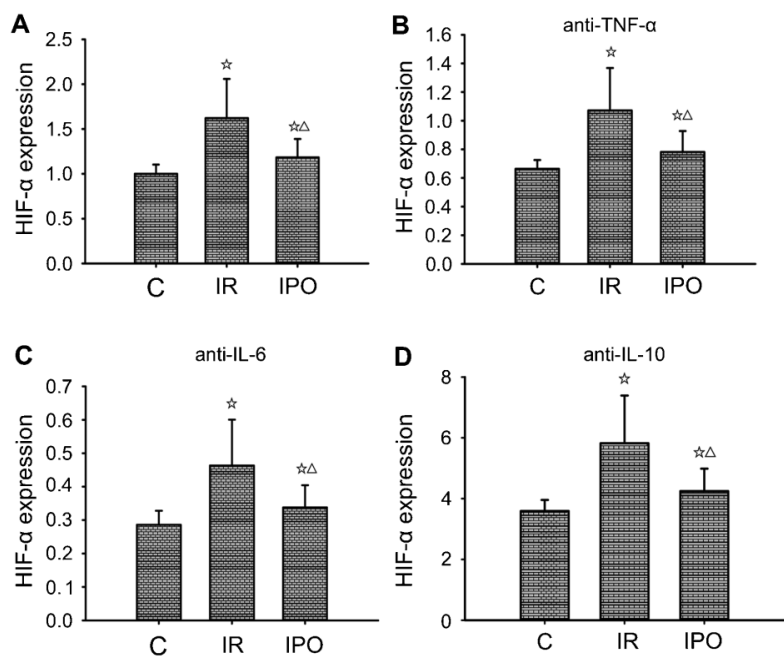

Figure 6. Effects of anti-TNF- $\alpha$, anti-IL-6, and anti-IL-10 treatment on hypoxia-inducible factor- $1 \alpha(\mathrm{HIF}-1 \alpha)$ expression in skeletal muscle ischemia-reperfusion (IR) injury that occurs after $3 \mathrm{~h}$ ischemia and $3 \mathrm{~h}$ reperfusion. A, Quantification of HIF- $1 \alpha$ expression. $B$, Effect of anti-TNF- $\alpha$ on the expression of HIF- $1 \alpha$. $C$, Effect of anti-IL-6 on the expression of HIF-1 $\alpha$. D, Effect of anti-IL-10 on the expression of HIF-1 $\alpha$. Data are reported as means $\pm \mathrm{SD}$. ${ }^{i} \mathrm{P}<0.05$ vs sham-operated group $(\mathrm{C}) ;{ }^{\triangle} \mathrm{P}<0.05$ vs IR group (one-way ANOVA). 
measurements after $3 \mathrm{~h}$ of ischemia, a model in which we expected a higher prevalence of skeletal muscle ischemia injuries. In the present study, we set up a model of lower limb IR injury on rats, and applied a previously used algorithm (three cycles, consisting of $30 \mathrm{~s}$ reperfusion-30 s ischemia each at the start of reperfusion) described as the most efficient postconditioning method in dogs (15).

In our experimental setting, postconditioning had a positive effect on IR injury of the muscle tissues. The plasma concentration of certain necroenzymes (LDH, CK) and the histopathological samples taken from the quadriceps femoris muscle demonstrated a significant difference between the IPO and IR groups.

Increasing clinical and experimental evidence indicate that proinflammatory cytokines play a critical role in the cascade of events resulting in injury from IR $(5,23)$. According to recent studies, the underlying cause of skeletal muscle injury after limb IR injury is a systemic inflammatory response $(2,23)$. Leukocytes and endothelial cells are the primary cell types involved in cytokine production due to IR injury. IL-1 $\beta$ and TNF- $\alpha$ are two such up-regulated cytokines, with proinflammatory local and systemic effects that can be detected soon after reperfusion of the ischemic lower extremity $(5,24)$. TNF- $\alpha$ causes alterations in the endothelial cell that result in capillary leak (25). It also causes the expression of IL-6 and IL-8, as well as of monocyte chemotactic protein-1 (MCP-1) (26). IL-6, in turn, further contributes to endothelial permeability and the production of acute-phase reactants from the liver, while IL-8 results in neutrophil chemotaxis and adhesion. MCP-1 is a chemokine that results in recruitment of circulating monocytes to areas of inflammation and injury (27). The concept that IL-10 acts as an anti-inflammatory molecule was suggested primarily by studies showing inhibition of the synthesis of a large spectrum of proinflammatory cytokines by different cells, particularly of the monocytic lineage. Thus, IL-10 modulates proinflammatory cytokine production and tissue injury following ischemia and reperfusion injury (28). The net result of cytokine up-regulation due to IR injury is loss of endothelial integrity, in addition to the recruitment and activation of leukocytes.

The results obtained in the present study showed that serum TNF- $\alpha$ and IL- 6 decreased while IL-10 increased in the IPO group compared with the IR group. These data indicated that IPO against skeletal muscle IR injury may have a relationship to decreased inflammatory reaction caused by lower limb IR injury that triggers a systemic inflammatory response. This is consistent with the results of a recent study that suggested that postconditioning ameliorates pathophysiological IR events during the early reperfusion phase (29). In addition, histological specimens taken at $3 \mathrm{~h}$ postreperfusion showed significant reductions in acute inflammatory reaction, edema, and muscle fiber necrosis in the IPO group compared with the IR group, and these findings were supported by the lower levels of TNF- $\alpha$ and IL- 6 content in the IPO group and the higher level of TNF- $\alpha$ and IL-6 content found in the IR group.

The pathophysiology of IPO has been reviewed recently (19). There is evidence to indicate that neutrophil accumulation is a key event in muscle infarction in skeletal muscle IR injury $(29,30)$. Our earlier experiments indicated that IPO attenuated gastric ischemic injury after limb IR injury, and the mechanism may be related to inhibition of oxygen free radicals and inflammatory cytokines that cause organ damage (31).

The IR injury of extensive muscle tissue mass and the sensitive vascular tissues and endothelium often leads to systemic complications with distant organ damage of major clinical importance, a phenomenon called reperfusion syndrome (32). It has, essentially, two components: a local component that can result in increasing the regional damage from hypoxia-ischemia, and a systemic component that can result in cytokine activation and simultaneous multiple organ dysfunction from the reperfused ischemic tissue.

Hypoxia, or lowered physiological oxygenation, is a component of many disease states as well as with a variety of surgical procedures. The study of hypoxia and the hypoxia-inducible transcription factor HIF-1 has engendered a better understanding of the way that cells perceive oxygenation at a molecular level, the response mechanisms that interact with the transcriptional machinery of the cell, and the organism adaptation and survival that the resulting response enables. Thus, multiple mechanisms of hypoxic response act through HIF- $1 \alpha$.

$\mathrm{HIF}-1 \alpha$ is a master regulator of essential adaptive responses to hypoxia, whose expression and transcriptional activity increase exponentially with decreases in levels of cellular oxygen. In tumors, HIF-1 $\alpha$ regulates proliferation, apoptosis, metastatic spread, and glucose metabolism by acting as a transcription factor for crucial proteins (33). Additionally, HIF-1 $\alpha$ is a major regulator of VEGF expression under hypoxia (10), was up-regulated both at mRNA and protein levels, and was located in the nucleus, suggesting that this may be the main pathway for VEGF induction in acute ischemia. A recent study suggested that mutant HIF$1 \alpha$ can improve mature angiogenesis and tissue perfusion in ischemic rabbit skeletal muscle (11). In the present study, the IPO group showed a marked decrease in the level of HIF$1 \alpha$ expression in myocyte cytoplasm and nuclei, vascular endothelial cytoplasm and nuclei, and inflammatory cytoplasm and nuclei of skeletal muscle tissue compared to the IR group. These results indicated that the protective effects of IPO against skeletal muscle IR injury may be related to the involvement of the expression of HIF- $1 \alpha$, which is often considered to be a master regulator of VEGF expression and angiogenesis in hypoxia, and can promote angiogenesis and improve tissue perfusion.

Proinflammatory cytokines, IL-1 $\beta$, and TNF- $\alpha$ have each been shown to stabilize HIF-1 $\alpha$ protein, suggesting that HIF$1 \alpha$ functions can be recruited by tissue inflammation $(34,35)$. 
Generally speaking, proinflammatory mediators promote angiogenesis, and the proangiogenic effects mediated by IL-1 and TNF- $\alpha$ support such a hypothesis (36), whereas interferon- $\gamma$ and IL-12 are associated with anti-angiogenesis (37). Our study showed that serum TNF- $\alpha$, IL-6, and IL-10 content significantly increased in the IR group, as well as increased HIF- $1 \alpha$ expression with progression to skeletal muscle IR injury from that group, and when serum TNF- $\alpha$ and IL-6 content were reduced, while IL-10 increased, the expression of HIF- $1 \alpha$ also decreased in the IPO group. It showed that inflammatory cytokines (TNF- $\alpha$, IL-6, and IL-10) could induce HIF-1 $\alpha$ protein

\section{References}

1. Norwood MG, Bown MJ, Sayers RD. Ischaemia-reperfusion injury and regional inflammatory responses in abdominal aortic aneurysm repair. Eur J Vasc Endovasc Surg 2004; 28: 234-245, doi: 10.1016/j.ejvs.2004.03.026.

2. Gillani S, Cao J, Suzuki T, Hak DJ. The effect of ischemia reperfusion injury on skeletal muscle. Injury 2012; 43: 670675, doi: 10.1016/j.injury.2011.03.008.

3. Ascer E, Gennaro M, Cupo S, Mohan C. Do cytokines play a role in skeletal muscle ischemia and reperfusion? $J$ Cardiovasc Surg 1992; 33: 588-592.

4. Seekamp A, Warren JS, Remick DG, Till GO, Ward PA. Requirements for tumor necrosis factor-alpha and interleukin-1 in limb ischemia/reperfusion injury and associated lung injury. Am J Pathol 1993; 143: 453-463.

5. Yassin MM, Harkin DW, Barros D'Sa AA, Halliday MI, Rowlands BJ. Lower limb ischemia-reperfusion injury triggers a systemic inflammatory response and multiple organ dysfunction. World J Surg 2002; 26: 115-121, doi: 10.1007/s00268-001-0169-2.

6. Zhang F, Hu EC, Gerzenshtein J, Lei MP, Lineaweaver WC. The expression of proinflammatory cytokines in the rat muscle flap with ischemia-reperfusion injury. Ann Plast Surg 2005; 54: 313-317.

7. Faxon DP, Gibbons RJ, Chronos NA, Gurbel PA, Sheehan F. The effect of blockade of the CD11/CD18 integrin receptor on infarct size in patients with acute myocardial infarction treated with direct angioplasty: the results of the HALT-MI study. J Am Coll Cardiol 2002; 40: 1199-1204, doi: 10.1016/S0735-1097(02)02136-8.

8. Flaherty JT, Pitt B, Gruber JW, Heuser RR, Rothbaum DA, Burwell LR, et al. Recombinant human superoxide dismutase (h-SOD) fails to improve recovery of ventricular function in patients undergoing coronary angioplasty for acute myocardial infarction. Circulation 1994; 89: 19821991, doi: 10.1161/01.CIR.89.5.1982.

9. Tuomisto TT, Rissanen TT, Vajanto I, Korkeela A, Rutanen J, Yla-Herttuala S. HIF-VEGF-VEGFR-2, TNF-alpha and IGF pathways are upregulated in critical human skeletal muscle ischemia as studied with DNA array. Atherosclerosis 2004; 174: 111-120, doi: 10.1016/j.atherosclerosis.2004.01.015.

10. Forsythe JA, Jiang BH, lyer NV, Agani F, Leung SW, Koos $\mathrm{RD}$, et al. Activation of vascular endothelial growth factor gene transcription by hypoxia-inducible factor 1 . Mol Cell Biol 1996; 16: 4604-4613. accumulation in myocyte cytoplasm and nuclei, vascular endothelial cytoplasm and nuclei, and inflammatory cytoplasm and nuclei of skeletal muscle tissue under hypoxia conditions.

In summary, data from this study provide evidence that ischemic postconditioning can attenuate skeletal muscle damage caused by limb IR, and the mechanisms might be related to involvement of HIF- $1 \alpha$ expression in the hindlimb IR injury-triggered inflammatory response. Further understanding of these mechanisms will be, undoubtedly, a major contribution to research of the pathogenesis and therapies of limb IR injury.

11. Li M, Liu C, Bin J, Wang Y, Chen J, Xiu J, et al. Mutant hypoxia inducible factor-1alpha improves angiogenesis and tissue perfusion in ischemic rabbit skeletal muscle. Microvasc Res 2011; 81: 26-33, doi: 10.1016/j.mvr.2010.09.008.

12. Angelo LS, Kurzrock R. Vascular endothelial growth factor and its relationship to inflammatory mediators. Clin Cancer Res 2007; 13: 2825-2830, doi: 10.1158/1078-0432.CCR06-2416.

13. Pedowitz RA, Gershuni DH, Schmidt AH, Friden J, Rydevik $\mathrm{BL}$, Hargens AR. Muscle injury induced beneath and distal to a pneumatic tourniquet: a quantitative animal study of effects of tourniquet pressure and duration. J Hand Surg Am 1991; 16: 610-621, doi: 10.1016/0363-5023(91)90183-C.

14. Souza Filho MV, Loiola RT, Rocha EL, Simao AF, Gomes AS, Souza $\mathrm{MH}$, et al. Hind limb ischemic preconditioning induces an anti-inflammatory response by remote organs in rats. Braz J Med Biol Res 2009; 42: 921-929, doi: 10.1590/ S0100-879X2009005000025.

15. Zhao ZQ, Corvera JS, Halkos ME, Kerendi F, Wang NP, Guyton RA, et al. Inhibition of myocardial injury by ischemic postconditioning during reperfusion: comparison with ischemic preconditioning. Am J Physiol Heart Circ Physiol 2003; 285: H579-H588.

16. Ren C, Gao X, Steinberg GK, Zhao H. Limb remotepreconditioning protects against focal ischemia in rats and contradicts the dogma of therapeutic time windows for preconditioning. Neuroscience 2008; 151: 1099-1103, doi: 10.1016/j.neuroscience.2007.11.056.

17. Carter WO, Bull C, Bortolon E, Yang L, Jesmok GJ, Gundel $\mathrm{RH}$. A murine skeletal muscle ischemia-reperfusion injury model: differential pathology in BALB/C and DBA/2N mice. J Appl Physiol 1998; 85: 1676-1683.

18. Dormandy JA, Rutherford RB. Management of peripheral arterial disease (PAD). TASC Working Group. TransAtlantic Inter-Society Consensus (TASC). J Vasc Surg 2000; 31: S1-S296, doi: 10.1016/S0741-5214(00)81002-2.

19. Gyurkovics E, Aranyi P, Stangl R, Onody P, Ferreira G, Lotz $\mathrm{G}$, et al. Postconditioning of the lower limb - protection against the reperfusion syndrome. J Surg Res 2011; 169: 139-147, doi: 10.1016/j.jss.2009.10.014.

20. Labbe R, Lindsay $\mathrm{T}$, Walker PM. The extent and distribution of skeletal muscle necrosis after graded periods of complete ischemia. J Vasc Surg 1987; 6: 152-157, doi: 10.1067/mva. 1987.avs0060152. 
21. Belkin M, Brown RD, Wright JG, LaMorte WW, Hobson RW. A new quantitative spectrophotometric assay of ischemiareperfusion injury in skeletal muscle. Am J Surg 1988; 156: 83-86, doi: 10.1016/S0002-9610(88)80360-X.

22. Steinau $\mathrm{H}-\mathrm{U}$. Major limb replantation and postischemia syndrome: Investigation of acute ischemia-induced myopathy and reperfusion injury. New York: Springer Verlag; 1988.

23. Eliason JL, Wakefield TW. Metabolic consequences of acute limb ischemia and their clinical implications. Semin Vasc Surg 2009; 22: 29-33, doi: 10.1053/j.semvascsurg.2009.01.001.

24. Ascer E, Mohan C, Gennaro M, Cupo S. Interleukin-1 and thromboxane release after skeletal muscle ischemia and reperfusion. Ann Vasc Surg 1992; 6: 69-73, doi: 10.1007/ BF02000671.

25. Sato N, Goto T, Haranaka K, Satomi N, Nariuchi H, ManoHirano $\mathrm{Y}$, et al. Actions of tumor necrosis factor on cultured vascular endothelial cells: morphologic modulation, growth inhibition, and cytotoxicity. J Natl Cancer Inst 1986; 76 : 1113-1121.

26. Kunkel SL, Remick DG, Strieter RM, Larrick JW. Mechanisms that regulate the production and effects of tumor necrosis factor-alpha. Crit Rev Immunol 1989; 9: 93-117.

27. Shireman PK. The chemokine system in arteriogenesis and hind limb ischemia. J Vasc Surg 2007; 45 (Suppl A): A48A56, doi: 10.1016/j.jvs.2007.02.030.

28. Seekamp A, Jochum M, Ziegler M, van Griensven M, Martin M, Regel G. Cytokines and adhesion molecules in elective and accidental trauma-related ischemia/reperfusion. J Trauma 1998; 44: 874-882, doi: 10.1097/00005373-19980500000022.

29. Park JW, Kang JW, Jeon WJ, Na HS. Postconditioning protects skeletal muscle from ischemia-reperfusion injury. Microsurgery 2010; 30: 223-229.
30. McAllister SE, Ashrafpour H, Cahoon N, Huang N, Moses MA, Neligan PC, et al. Postconditioning for salvage of ischemic skeletal muscle from reperfusion injury: efficacy and mechanism. Am J Physiol Regul Integr Comp Physiol 2008; 295: R681-R689, doi: 10.1152/ajpregu.90303.2008.

31. Wang $T$, Leng $Y F$, Zhang $Y$, Kang $Y Q$, Xue X, Zhang $Y$. [Preventive effects of ischemic postconditioning and penehyclidine hydrochloride on gastric against ischemia-reperfusion injury in rats]. Zhonghua Yi Xue Za Zhi 2011; 91: 11301135.

32. Blaisdell FW. The pathophysiology of skeletal muscle ischemia and the reperfusion syndrome: a review. Cardiovasc Surg 2002; 10: 620-630, doi: 10.1016/S09672109(02)00070-4.

33. Hirota K. Hypoxia-inducible factor 1 , a master transcription factor of cellular hypoxic gene expression. $J$ Anesth 2002; 16: 150-159, doi: 10.1007/s005400200011.

34. Wilson J, Balkwill F. The role of cytokines in the epithelial cancer microenvironment. Semin Cancer Biol 2002; 12: 113-120, doi: 10.1006/scbi.2001.0419.

35. Naldini A, Pucci A, Bernini C, Carraro F. Regulation of angiogenesis by Th1- and Th2-type cytokines. Curr Pharm Des 2003; 9: 511-519, doi: 10.2174/1381612033391423.

36. Jung $Y$, Isaacs JS, Lee S, Trepel J, Liu ZG, Neckers L. Hypoxia-inducible factor induction by tumour necrosis factor in normoxic cells requires receptor-interacting proteindependent nuclear factor kappa B activation. Biochem $J$ 2003; 370: 1011-1017, doi: 10.1042/BJ20021279.

37. Jung YJ, Isaacs JS, Lee S, Trepel J, Neckers L. IL-1betamediated up-regulation of HIF-1alpha via an NFkappaB/ COX-2 pathway identifies HIF-1 as a critical link between inflammation and oncogenesis. FASEB J 2003; 17: 21152117. 